\title{
Manufacture of Glass Foam by Predominantly Direct Microwave Heating of Recycled Glass Waste
}

\author{
${ }^{1}$ Sorin Mircea Axinte, ${ }^{2}$ Ludan Paunesau, ${ }^{3}$ Marius Forin Dragoesar, 4 Ana Casandra Sebe \\ 1Department of Applied Chemistry and Materials Science, University “Politehnica” of Bucharest, \\ Romania; \\ 2,3Daily Sourcing \& Research SRL Bucharest, Romania; \\ ${ }^{4}$ Cosfel Actual SRL Bucharest, Romania; \\ sorinaxinte@yahoo.com
}

\begin{abstract}
The paper presents authors' contribution to the improvement of the manufacturing technique of foam glass using the microwave energy. Due to the physical and mechanical characteristics, this material, obtained by the sintering process of waste glass at high temperature, constitutes a viable replacer of existing similar materials, used especially in construction. Unlike the conventional heating methods used worldwide, the company Daily Sourcing \& Research SRL Bucharest tested lately microwave heating techniques in the manufacturing process of foam glass. In the paper it is presented an original method based on the feature of the powder mixture composed by waste glass (over $97 \mathrm{wt} . \%$ ) and the foaming agent (calcium carbonate) to absorb the microwave energy and convert it to heat since the ambient temperature, using a silicon carbide and silicon nitride (80/ 20 weight ratio) crucible with thin wall (2.5 $\mathrm{mm}$ ), which allows both a preponderantly direct heating and partially an indirect heating of the material. The main parameters of the process (specific consumption of energy, heating speed, process temperature and duration) were significant improved compared to the previous experiments.
\end{abstract}

Keywords Glass foam; Glass waste; Calcium carbonate; Microwave heating; Silicon carbide.

\section{Introduction}

Microwave heating is a fast, economical and "clean" process, known since the 1930s. However, until the end of the last century, the fields of applicability were very limited. The microwave applications in the household in the food preparation are well known. Industrially, the microwave energy was used only for vulcanization of rubber or for different drying processes. Only in the last decade, it has been experimentally found that many other types of materials can be efficiently heated with microwaves: organics, ceramics, polymers, metals, glass, etc., but the results remained at the level of experiment [1].

One such example is the field of industrial manufacture of glass foams from recycled glass waste. The manufacturing technique involves heating the raw material with a suitable foaming agent at high

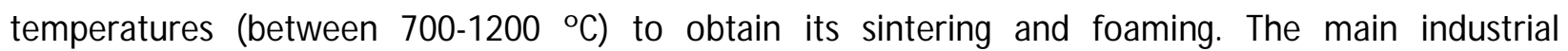


Sorin Mircea Axinte, Lucian Paunescu, Marius Florin Dragoescu, Ana Casandra Sebe; Manufacture of Glass Foam by Predominantly Direct Microwave Heating of Recycled Glass Waste, Transactions on Networks and Communications, Volume 7 No. 4, August (2019); pp: 37-45

manufacturers (Misapor Switzerland, Pittsburgh Corning, etc.) of glass foam, usable as a substitute for existing building materials due to their remarkable physical and mechanical characteristics (mainly, low density, low thermal conductivity, acceptable mechanical resistance), still adopt conventional heating techniques (burning fossil fuels or electrical resistances)[2, 3]. It should be mentioned that even experimental works in this field, in fact many in recent years, are not interested in energy problems, but only technological. The explanation of the mistrust regarding the application of the microwave energy should be sought in the paper [4] published in 1997, which states that the commercial glass is very few

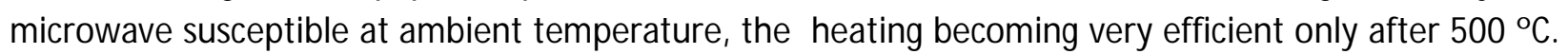
Other works also confirm that theoretically, due to the high content of microwave transparent materials $\left(\mathrm{SiO}_{2}, \mathrm{Al}_{2} \mathrm{O}_{3}\right)$ in the glass composition, the heating process should take place with difficulty at ambient temperature due to the low electrical conductivity. Its value increases rapidly with increasing the temperature and simultaneously, the energy efficiency of the microwave heating significantly increases [5-7]. This statement was taken up by J. Hurley in 2003 in a UK market survey [2], which concludes that an industrial glass foam oven should have two distinct zones: a zone with temperatures below 500 ㄷ heated by conventional methods, and one with temperatures above 500 ㄷ microwave powered, which would be an unprofitable technology. In reality, however, due to the inherent presence in the glass composition of some contaminants $\left(\mathrm{Fe}_{2} \mathrm{O}_{3}, \mathrm{Cr}_{2} \mathrm{O}_{3}\right)$, even in small ratios, the microwave heating can occur with normal efficiency starting from the ambient temperature [8].

Knox and Copley's theory was experimentally contradicted [9] by researchers from the Romanian company Daily Sourcing \& Research Bucharest, who have recently conducted numerous experiments following the application of microwave heating in the field of glass foam production. The experimental results, published both in Romania and worldwide [9-14], confirmed the viability of the adopted solutions, the foamed products being qualitatively similar to those obtained by conventional methods.

An important aspect of the microwave heating of the powder mixture consisting of glass waste, foaming agent and any other mineral additions, is the difficulty of achieving the integral direct heating through the direct contact between the microwave field and the glass-based material. Several experiments have shown that the direct heating of the microwave glass waste is inadequate to obtain a homogeneous macrostructure in the mass of the foamed product [9]. It is known that the direct microwave heating of any solid material is initiated in its core, where the maximum temperature is reached, the heat being then transferred to the peripheral areas of the material [15]. The heating speed is very high (over 35-40 $9 \mathrm{C}$ min) and this fact is completely not indicated for the sintering / foaming process. The speeds recommended in the literature $[3,16]$ as well as those achieved in the own previous experimental processes are between 5-25 ㅇ/ min, varying depending on the type and quantity of the material, the type and weight ratio of the foaming agent, the manufacturing technique adopted, etc. Taking into account the above aspects, Daily Sourcing \& Research has tested several types of microwave susceptible ceramic crucibles (silicon carbide, graphite, graphite +silicon carbide, silicon carbide +silicon nitride) as well as different thicknesses of their wall (between $2.5-20 \mathrm{~mm}$ ). The use of such a crucible changes the type of microwave heating to indirect heating. This systemslows down the process of making glass foam, because in the most cases the wall of the crucible absorbs all electromagnetic waves, heats up quickly, and transfers the heat to the material through the well-known conventional heating processes (mainly, thermal conductivity and radiation). Thus, the indirect heating takes place from the outside to the inside. 
In the case of crucibles with wall thickness of 2.5-3.5 mm, it was found that the microwaves partially penetrate the ceramic wall, making both its heating and the direct contact with the material subjected to heating. In this way, the core of the material is heated, the heat transfer being carried out fromthe inside to the outside. On the other hand, simultaneously, the inner surface of the crucible transmits heat inward.

The experiments presented below show the results obtained in a predominantly direct heating case, using a crucible of silicon carbide and silicon nitride in the mass ratio $80 / 20$, with the wall thickness of $2.5 \mathrm{~mm}$.

\section{Methods and materials}

\subsection{Methods}

In principle, the production of glass foam from recycled glass waste is based on sintering at high temperature a powder mixture formed from glass waste and a suitable foaming agent. The foaming consists in the release of a gas in the softened mass of the mixture at a temperature close to its melting point, by thermal decomposition or oxidation of the foaming agent. Generally, the most commonly used foaming agents are carbonates (calcium carbonate, sodium carbonate), powder carbon, black carbon, silicon carbide, etc. The carbonates decompose, releasing carbon monoxide or carbon dioxide, while the other named agents oxidize, releasing the same type of gas. Due to the adequate viscosity of the material, the gas bubbles remain blocked in its mass, and by subsequent cooling they forma homogeneous porous structure. The experiment carried out in Daily Sourcing \& Research took place in a $0.8 \mathrm{~kW}$-microwave oven, of the type used in the household for food preparation, equipped with only one microwave generator, but adapted for operating conditions at temperatures up to $1200 \stackrel{\circ}{ }$ (Figure 1a). The finegrained powder material was loaded and pressed into a crucible of silicon carbide and silicon nitride in the weight ratio $80 / 20$, having a wall thickness of $2.5 \mathrm{~mm}$ (Figure 1b). The crucible has the outer diameter of $\varnothing 120 \mathrm{~mm}$ and the height of $100 \mathrm{~mm}$ and has a lid of a silicon carbide plate with a thickness of $10 \mathrm{~mm}$. The total capacity of the crucible is $986 \mathrm{~cm}^{3}$, allowing a maximum load of the glass-based powder mixture of about $1.28 \mathrm{~kg}$ (average density of the pressed mixture being determined experimentally at about 1.3 $\mathrm{g} / \mathrm{cm}^{3}$. The wall of the crucible made of a material with high microwave susceptibility will partially absorb the radiation of the microwave field, while most of them will penetrate it and will come in direct contact with the material subjected to heating. This type of mixed heating (direct and indirect) has the role of increasing the efficiency of heating over the indirect one and, at the same time, of diminishing the undesirable effect of the destruction of the interior structure of the material, which characterizes the direct heating. Because the microwave heating process is inversely oriented compared to the conventional one, i.e. from the inside to the outside, the crucible containing the powder mixture is protected on all its outer surfaces with ceramic fiber mattresses to reduce heat loss outside the system.

The thermal control of the foaming process is based on the indications of a Pyrovar type radiation pyrometer mounted above the oven in its central axis (see Figure 1a). For viewing the upper surface of the material into crucible, holes of about $30 \mathrm{~mm}$ both in the upper metal wall of the oven and in the silicon carbide lid and the ceramic fiber mattresses layer that protects the ceramic lid were provided.

Because the foaming agent adopted during the experiment is calcium carbonate, the decomposition reaction that characterizes the foaming process is:

$$
\mathrm{CaCO}_{3}=\mathrm{CaO}+\mathrm{CO}_{2}
$$


According to the literature [17], the reaction (1) can start at $740{ }^{\circ}$ Cand end at less than 900 ㄷ. Generally, the foaming process of soda-lime glass (commercial glass bottle) takes place between 800-900 ㄷ, varying depending on the quantity and quality of the glass waste, the weight ratio of foaming agent, fineness of granulation of materials, etc.

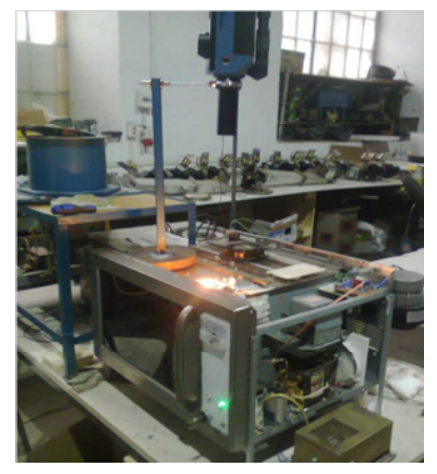

a

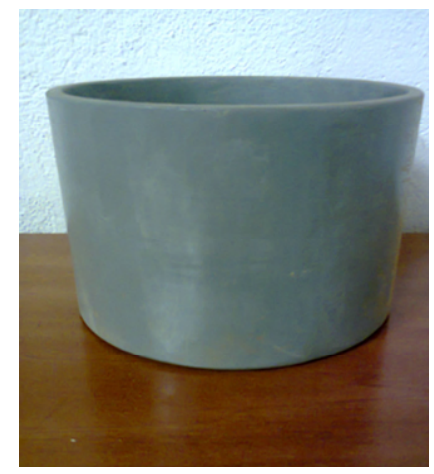

b

Figure 1. The experimental microwave equipment a-0.8kW-miarowave oven; b- ceramic cruable.

\subsection{Materials}

The raw material used in the experiments was that from the recycling of commercial glass containers. These are soda-lime glasses, with the largest spread between the glass waste. Only the colourless glass wastes were selected. The chemical composition of this type of glass is shown in Table 1.

Table 1 Chemical composition of the colourless sodalime glass.

\begin{tabular}{|c|c|c|c|c|c|c|}
\hline $\mathbf{S O}_{\mathbf{2}}$ & $\mathbf{A l}_{2} \mathbf{O}_{3}$ & $\mathbf{C a O}$ & $\mathbf{F e}_{2} \mathbf{O}_{\mathbf{3}}$ & $\mathbf{M g O}$ & $\mathbf{N b}_{2} \mathbf{O}$ & $\mathbf{O r}_{\mathbf{2}} \mathbf{O}_{\mathbf{3}}$ \\
\hline 71.7 & 1.9 & 12.0 & 0.05 & 1.0 & 13.3 & 0.05 \\
\hline
\end{tabular}

The glass waste was crushed and ground into a ball mill. The grain size of the material was limited to maximum $130 \mu \mathrm{m}$ following the sieving. Calcium carbonate as a foaming agent was used such as it was purchased from the market, having a very fine grain size below $40 \mu \mathrm{m}$. The powder mixture containing glass waste and calcium carbonate was homogenized together with the water addition quantity in a small laboratory device.

\subsection{Characterization of the glass foam samples}

The main physical, mechanical and morphological characteristics (apparent density, porosity, thermal conductivity, compressive strength, water absorption, hydrolytic stability and microstructural configuration) of the foam glass samples under the conditions described above were investigated in the laboratory in the companies Daily Sourcing \& Research and Cosfel Actual as well as in the Department of Applied Chemistry and Materials Science of the University "Politehnica" of Bucharest, using common methods of analysis [18-21]. 


\section{Results and discussion}

\subsection{Results}

Four variants of the composition of the raw material and the foaming agent were tested in the $0.8 \mathrm{~kW}$ microwave oven under the conditions of the predominantly direct heating operation described above. The tests included weight ratios of the glass waste between $97.8-99.4 \%$ the rest being calcium carbonate (0.6-2.2\%). Also, an addition of water (10\%) was used, which reduces the viscosity of the foam mixture, contributes additionally to the foaming of the material and has the role of binder in pressing it before the thermal treatment begins [22]. The composition of each of the four tested variants is shown in Table 2.

Table 2. Composition of the tested variants.

\begin{tabular}{|c|c|c|c|}
\hline Variant & $\begin{array}{c}\text { Colourless } \\
\text { glass waste } \\
\text { wt.\% }\end{array}$ & $\begin{array}{c}\text { Caldium } \\
\text { carbonate } \\
\text { wt.\% }\end{array}$ & $\begin{array}{c}\text { Water } \\
\text { addition } \\
\text { wt.\% }\end{array}$ \\
\hline 1 & 97.8 & 2.2 & 10.0 \\
\hline 2 & 98.5 & 1.5 & 10.0 \\
\hline 3 & 99.0 & 1.0 & 10.0 \\
\hline 4 & 99.4 & 0.6 & 10.0 \\
\hline
\end{tabular}

The main functional parameters of the sintering and foaming process corresponding to the four compositional variants are presented in Table 3.

Table 3. Main parameters of the sintering foaming process.

\begin{tabular}{|c|c|c|c|c|c|c|c|c|}
\hline Variant & \multicolumn{2}{|c|}{$\begin{array}{c}\text { Raw material } \\
\text { quantity, g }\end{array}$} & $\begin{array}{c}\text { Process } \\
\text { temperature } \\
\text { oC }\end{array}$ & $\begin{array}{c}\text { Process } \\
\text { duration } \\
\text { min }\end{array}$ & $\begin{array}{c}\text { wet } \\
\text { dryerage } \\
\text { heating } \\
\text { speed } \\
\text { od } \mathbf{~ m i n}\end{array}$ & $\begin{array}{c}\text { Glass } \\
\text { foam } \\
\text { quantity } \\
\text { g }\end{array}$ & $\begin{array}{c}\text { Index of } \\
\text { volume } \\
\text { growth }\end{array}$ & $\begin{array}{c}\text { Specific } \\
\text { consumption } \\
\text { of electricity } \\
\text { kWh/ kg }\end{array}$ \\
\hline 1 & 490 & 539 & 832 & 35 & 23.2 & 475 & 2.40 & 0.98 \\
\hline 2 & 490 & 539 & 830 & 34 & 23.8 & 476 & 2.30 & 0.95 \\
\hline 3 & 490 & 539 & 829 & 33 & 24.5 & 476 & 2.25 & 0.92 \\
\hline 4 & 490 & 539 & 828 & 34 & 23.8 & 474 & 1.80 & 0.96 \\
\hline
\end{tabular}

According to the data in Table 3, the quantities of dry and wet powder mixture loaded in the crucible were kept at constant values (490 g and $539 \mathrm{~g}$, respectively). In these conditions, the temperature and the duration of the process had slightly significant variations, between $828-832{ }^{\circ} \mathrm{C}$ and $33-35 \mathrm{~min}$, respectively. The average heating speed reached high values between $\left.23.2-24.5^{\circ} \mathrm{Cl} / \mathrm{min}\right)$. The variation of the weight ratio of calcium carbonate (0.6-2.2 wt.\%) clearly influenced the index of volume growth of the foamed material, which reached a maximum of 2.40 , corresponding to the maximum value of the foaming agent ratio. The specific energy consumption had very low values (below $1 \mathrm{kWh} / \mathrm{kg}$ ) compared to other experimental microwave heating processes that use calcium carbonate as a foaming agent (over $2.5 \mathrm{kWh} / \mathrm{kg}$ ) made by Daily Sourcing \& Research $[9,10]$.

The physical, mechanical, and morphological characteristics of glass foams produced by predominantly direct microwave heating are shown in Table 4.

Table 4. Physical, medhanical, and monphological characteristics of glass foams. 
Sorin Mircea Axinte, Lucian Paunescu, Marius Florin Dragoescu, Ana Casandra Sebe; Manufacture of Glass Foam by Predominantly Direct Microwave Heating of Recycled Glass Waste, Transactions on Networks and Communications, Volume 7 No. 4, August (2019); pp: 37-45

\begin{tabular}{|c|c|c|c|c|c|c|}
\hline Veriant & $\begin{array}{l}\text { Apperent } \\
\text { density } \\
\text { g/ } \mathbf{~ a m}^{3}\end{array}$ & $\begin{array}{c}\text { Porosity } \\
\%\end{array}$ & $\begin{array}{l}\text { Compressive } \\
\text { strength } \\
\text { MPa }\end{array}$ & $\begin{array}{l}\text { Thermal } \\
\text { conductivity } \\
\text { W/ mK }\end{array}$ & $\begin{array}{c}\text { Water } \\
\text { absorption } \\
\%\end{array}$ & $\begin{array}{l}\text { Pore size } \\
\text { mm }\end{array}$ \\
\hline 1 & 0.18 & 91.8 & 1.18 & 0.040 & 1.1 & $1.5-3.0$ \\
\hline 2 & 0.20 & 90.9 & 1.20 & 0.042 & 0.8 & $1.0-1.6$ \\
\hline 3 & 0.19 & 91.4 & 1.21 & 0.043 & 0.8 & $0.8-1.5$ \\
\hline 4 & 0.20 & 91.0 & 1.21 & 0.044 & 0.6 & $0.7-0.9$ \\
\hline
\end{tabular}

Table 4 highlights that the glass foam samples produced by predominantly direct microwave heating have characteristics similar to those made by indirect microwave heating, and more so those manufactured by conventional methods. The apparent density and the thermal conductivity, which determine the quality of an insulating material usable in the building construction, have very low values $\left(0.18-0.20 \mathrm{~g} / \mathrm{cm}^{3}\right.$ and 0.040-0.044 W/ $\mathrm{m} \cdot \mathrm{K}$, respectively). The compressive strength (1.18-1.21 MPa) is considered acceptable, the water absorption is very low, practically insignificant, and the pore distribution in the sample section is homogeneous.

Figure 2 shows images of the longitudinal sections of the four glass foam samples.

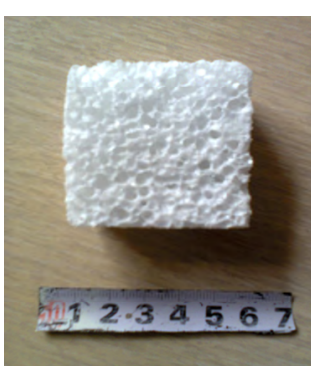

a

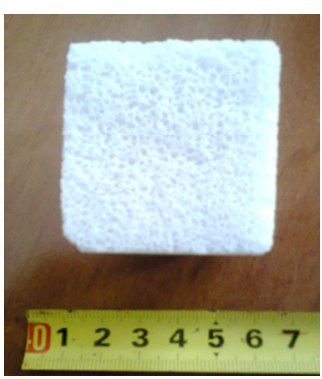

b

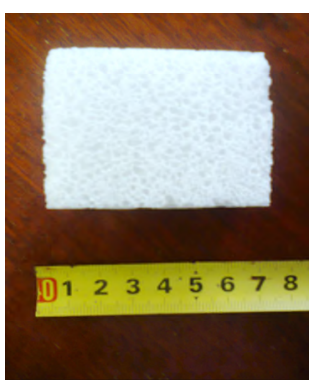

C

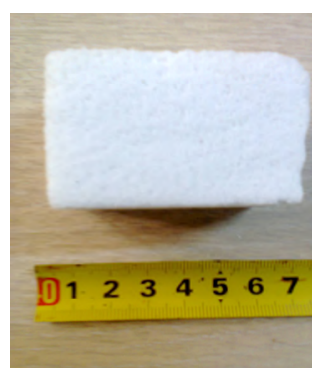

d

Figure 2 Images of the longitudinal sections of the glass foam samples a- sample 1; b- sample 2; c- sample 3; d- sample 4.

Images of the samples microstructure identified with a Smartphone Digital Microscope are shown in Figure 3.

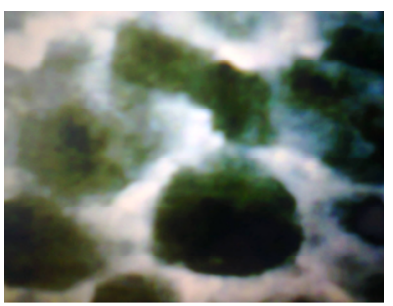

a

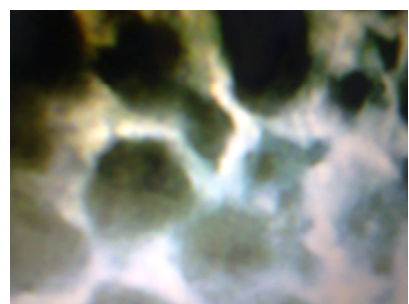

b

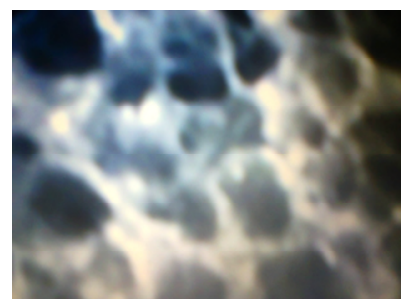

C

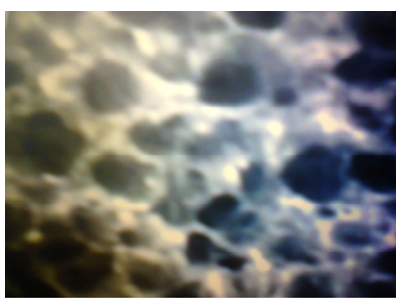

d

Figure 3. Images of the samples microstructure

a- sample 1; b- sample 2; c- sample 3; d- sample 4.

The tests for determining the hydrolytic stability of samples, using $0.15 \mathrm{ml}$ of $0.01 \mathrm{M} \mathrm{HO}$ solution to neutralize the extracted $\mathrm{Na}_{2} \mathrm{O}$, showed that the stability joins in the hydrolytic class 2. 


\subsection{Discussion}

The main objective of the research presented in the paper is to reduce the specific energy consumption in the process of manufacturing glass foam by predominantly direct heating without changing the product characteristics. It should be noted that the literature does not provide information on energy consumption. The only information comes from the market survey [2] referring to an average consumption of $100 \mathrm{kWh} / \mathrm{m}^{3}$-glass foam (i.e. about $0.40-0.67 \mathrm{kWh} / \mathrm{kg}$-glass foam, corresponding to the foam density between $0.15-0.25 \mathrm{~g} \mathrm{~cm}^{3}$ ). The specific energy consumption obtained in experiments, under conditions of a discontinuous operation of the oven, was between 0.92-0.98 kWh/ kg. According to the paper [1], an industrial microwave equipment should allow a high-energy power sources, the use of an unique internal protection feature, an uniform exposure to microwave, contributing to a significant reduction of the specific energy consumption with over $25 \%$ comparing to a small experimental equipment.

\section{Conclusion}

Glass cullet and especially post-consumer glass containers are a waste with a very high annual generation rate worldwide. The recycling of this waste has become a requirement both ecologically and materially due to the efficiency of its reuse in the production of glass foams as replacers of existing building materials on the market or in the manufacture of new glass as a raw material.

The use of the microwave energy is a fast, economical and "clean" technique applied far less in industry. In recent years, the Romanian company Daily Sourcing \& Research has made efforts to implement this unconventional technique in the field of glass foam manufacturing.

An unconventional heating technique with high energy efficiency is presented in the paper, being tested under experimental conditions in an adapted $0.8 \mathrm{~kW}$-microwave oven of the type of those very widespread in the household for preparing the food.

Using a low-cost foaming agent in the category of carbonates (calcium carbonate) and, implicitly, a thermal process at relatively moderate temperatures of 800-850 $9 \mathrm{C}$ as well as a predominantly direct microwave heating technique, low specific energy consumption values $(0.92-0.98 \mathrm{kWh} / \mathrm{kg})$ have been obtained.

Theoretically, by applying this technique to an industrial scale, the energy efficiency could be considerably higher by at least $25 \%$

The physical, mechanical and morphological characteristics of the glass foams produced under these conditions are almost similar to those made by conventional techniques.

\section{RHERENCES}

[8]. Kharissova, O., Kharissov, B. I., and Ruiz Valdez, J. J., Review: The use of microwave irradiation in the processing of glasses and their composites. Industrial \& Engineering Chemistry Research, 2010, 49(4): p. 1457-1466.

[9]. Hurley, J., Glass-Research and development, final report. A UK market survey for foamglass, March 2003. 
Sorin Mircea Axinte, Lucian Paunescu, Marius Florin Dragoescu, Ana Casandra Sebe; Manufacture of Glass Foam by Predominantly Direct Microwave Heating of Recycled Glass Waste, Transactions on Networks and Communications, Volume 7 No. 4, August (2019); pp: 37-45

[10]. Scarinci, G., Brusatin, G., and Bernardo, E., Glass Foams in Cellular ceramics: structure, manufacturing, properties and applications, G. Scheffler, P. Colombo, Editors, Wiley-VCH Verlag GmbH \& Co KGaA, Weinheim, Germany, 2005, p. 158-176.

[11]. Knox, M., and Copley, G., Use of microwave radiation for the processing of glass. Glass Technology, 1997, 38(3): p. 91-96.

[12]. Menezes, R. R., Souto, P. M., and Kiminami, R. H. G. A., Microwave fast sintering of ceramic materials. https://www.intechopen.com

[13]. Rahaman, M. N., Sintering of ceramics, CRCPress, Taylor \& Francis Group, Boca Raton, London, New York, 2007. https://books.google.ro

[14]. Kolberg, U., and Roemer, M., Reacting of glass. Ceramic Transaction, 2001, 111: p. 517-523.

[15]. Jones, D. A., et al., Microwave heating applications in environmental engineering-a review. Resources, Conservation and Recyding, 2002, 34: p. 75-90.

[16]. Paunescu, L, et al., Foam glass produced by microwave heating technique. Bulletin of Romanian Chemical Engineering Sodiety, 2017, 4(1): p. 98-108.

[17]. Paunescu, L, et al., Testing the use of microwave energy to produce foam glass. European Journal of Engineering and Technology, 2017, 5(4): p. 8-17.

[18]. Dragoescu, M. F., et al., Influence of the color of bottle glass waste on the characteristics of foamglass produced in microwave field. International Journal of Science and Engineering Investigations, 2018, 7(72): p. 95-100.

[19]. Dragoescu, M. F., et al., Foamglass with low apparent densityand thermal conductivity produced by microwave heating. Europea Journal of Engineering and Technology, 2018, 6(2): p. 1-9.

[20]. Dragoescu, M. F., et al., The use of microwave fields in the foaming process of flat glass waste. International Journal of Engineering Sciences \& Management Research, 2018, 5(4): p. 49-54.

[21]. Paunescu, L, et al., Glass foam from borosilicate glass waste produced in microwave field. Nonconventional Technologies Review, 2019, 23(1): p. 8-12.

[22]. Kitchen, H. J., et al., Modem microwave methods in solid-state inorganic materials dhemistry: From fundamentals to manufacturing. Chemical Reviews, 2014, 114: p. 1170-1206.

[23]. Rawlings R. D., Wu, J. P., and Boccaccini, A. R., Glass-ceramics: Their production from wastes-A review, Journal of Materials Science, 2006, 41(3): p. 733-761.

[24]. Koizumi, T., et al., Foaming agent for powder metallurgy production of aluminiumfoam. Materials Transactions, 2011, 52(4): p. 728-733.

[25]. Manual of weighing applications. Part 1. Density, 1999, https://docplayer.net>21731890-Manual-of-weighingapplications-part-1-density.htm

[26]. Anovitz, L M., and Cole, D. R., Characterization and analysis of porosity and pore structures. Review in Mineralogy \& Geochemistry, 2015, 80(1): p. 61-164. 
[27]. ISO 719: 1985 (review and confirmed in 2011), Glass-Hydrolytic resistance of glass grain at 98 ㄷ-Method of test and classification.

[28]. Calculation of the chemical durability (hydrolytic class, corrosion) of glass. http://glassproperties.com/chemical_durability

Karandashova, N. S., Goltsman, B., and Yatsenko, E. A., Analysis of influence of foaming mixture components on $\begin{array}{lllll}\text { structure and properties of foam } & 007 .\end{array}$ https://www.researchgate.net/publication/321354386_Analysis_of Influence_of Foaming_Mixture_Compon ents on Structure and Properties of Foam Glass 